\title{
Performance investigation of a novel hybrid deep- dehumidification process using liquid desiccant
}

\author{
Bowen Guan ${ }^{1}$, Jun Liu ${ }^{1}$, Xiaohua Liu ${ }^{1 *}$, Tao Zhang ${ }^{1}$, Liangliang Chen ${ }^{2}$, Xiaoyang Chen ${ }^{2}$ \\ ${ }^{1}$ Department of Building Science, Tsinghua University, Beijing, China \\ ${ }^{2}$ Beijing Sino-refine air-conditioning Co., LTD, Beijing, China
}

\begin{abstract}
As one of the essential dehumidification ways, liquid desiccant air conditioning system has developed quickly in recent years, especially in the deep dehumidification field. A novel hybrid deepdehumidification system using liquid desiccant driven by heat pump is proposed in this study to simplify the arrangement of air ducts and guarantee a competitive energy efficiency. In the proposed process, the regenerator, condensing dehumidifier and liquid dehumidifier are cascaded, and the process air flow through them sequentially. Heat pump cycle is utilized in the system, where the cooling capacity of evaporator is used to cool the liquid desiccant in dehumidifier, and the heating capacity of condenser is used for desiccant regeneration. The humidity ratio of the supplied air is as low as $2.6 \mathrm{~g} / \mathrm{kg}$. No extra regeneration air or corresponding air duct are needed in the proposed process, which obviously simplifies the layout of the system. Performance of the proposed system is then analysed by numerical results. It's indicated $17.5 \sim 29.2 \%$ energy is saved compared with the conventional deep dehumidification process with two-stage heat pump, with the outlet humidity ratio of $2.6 \mathrm{~g} / \mathrm{kg}$.
\end{abstract}

\section{Introduction}

Regarded as an energy-efficient approach of satisfying air humidity control requirement, liquid desiccant dehumidification has been researched by massive studies [1]. Compared with conventional condensing dehumidification methods, liquid desiccant dehumidification method shows advantages in utilizing renewable energy and cheaper fuels [2-4].

Different humidity ratios of the supply air are required by different industrial processes and environmental needs, where different liquid desiccant dehumidification systems are utilized. When requirement of the supply air is over $8 \mathrm{~g} / \mathrm{kg}$, usually, single-stage liquid desiccant dehumidifier would be sufficient to dehumidify the air, the schematic of its main components shown in Fig. 1(a). Lazzarin and Castellotti [5] have applied a single-stage module to the air handing process, and the supply air humidity ratio could be processed to $8.7 \sim 11.3 \mathrm{~g} / \mathrm{kg}$ with the coefficient of performance $(C O P)$ of the processor 3.2 4.2, when the outdoor air temperature $30^{\circ} \mathrm{C}$ and its humidity ratio 18.7 $\mathrm{g} / \mathrm{kg}$. Liu et al. [6] have studied a liquid desiccant outdoor air processor powered by a heat pump with twostage of total heat recovery and single-stage of dehumidification and regeneration. The supply air humidity ratio could be reduced to $11.0 \sim 11.5 \mathrm{~g} / \mathrm{kg}$ with the COP of 6.3 7.3, when the outdoor air temperature is $28^{\circ} \mathrm{C}$ and humidity ratio is $20 \sim 22 \mathrm{~g} / \mathrm{kg}$. In order to provide drier air, improve the COP or realize both of the above two aspects, the multiple-stage system has been introduced, the schematic of a two-stage system shown in Fig. 1 (b). Zhang et al. have investigated two-stage and three-stage liquid desiccant dehumidification processors driven by heat pump to realize deep dehumidification [7]. Under the two-stage process, the humidity ratio of $6.5 \sim 6.7 \mathrm{~g} / \mathrm{kg}$ could be realized with the $C O P$ of $6.5 \sim 6.7$, when the outdoor air temperature is $30.7 \sim 31.3^{\circ} \mathrm{C}$ and its humidity ratio is $18.4 \sim 18.7 \mathrm{~g} / \mathrm{kg}$. As for the three-stage process, the humidity ratio of 3.4 3.6 could be realized with the $C O P$ of 2.8 , when the outdoor air temperature is $30.2 \sim 31.3^{\circ} \mathrm{C}$.

In recent years, hybrid dehumidification systems using liquid desiccant have become popular owing to a reduction in their energy consumption. Chen et al. [8] investigated on a hybrid desiccant dehumidification and evaporative cooling system with partial circulation air was explored by fully making use of dry return air from air-conditioned space, and an attractive energy saving ratio of $23.5 \%$ could be achieved under Hong Kong weather condition, compared with the conventional vapour compression air-conditioning system. $\mathrm{Su}$ and Zhang [9] proposed a hybrid compression-absorption refrigeration air-conditioning system combined with liquid desiccant dehumidification, the primarily energy efficiency of the system was $34.97 \%$ higher than that of traditional absorption refrigeration air-conditioning system at the same operation condition. Su et al. [10] developed a novel liquid desiccant system integrated with a concentrated photovoltaic/thermal collector for deep dehumidification. Simulation studies indicated the proposed system has a superior power saving ability of

\footnotetext{
* Corresponding author: 1xh@,tsinghua.edu.cn
} 
$55.65 \%$ comparing with the conventional one. Shan et al. [11] proposed a hybrid refrigerant system consisting of a conventional chiller combined with a liquid desiccant dehumidification and evaporative cooling subsystem in summer, and the electric coefficient of performance of the system was revealed $10.3 \%$ higher than the conventional vapour compression system. Thu et al. [12] evaluated the feasibility of hybrid dehumidification + mechanical vapour compression systems. It was demonstrated that the break-even $C O P$ for the dehumidifier ranges from 9 to 17 (Carnot approach) and 4.3 to 6.8 (ideal cycle), depending on the requirement of the outdoor air ratio and the temperature of the supply air.

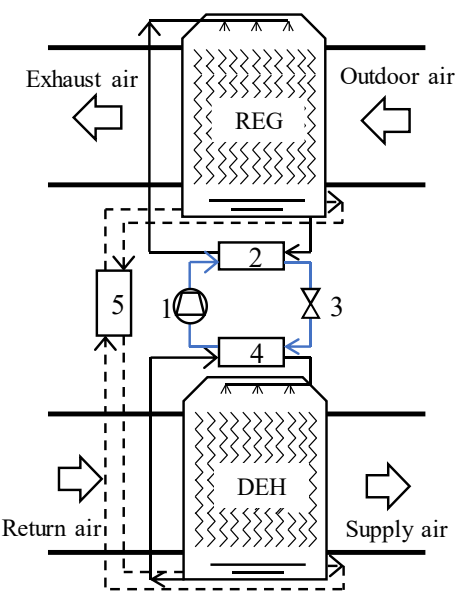

1-Compressor; 2-Condenser; 3- Expansive valve; 4-Evaporator; 5-Exchanger (a) Single-stage liquid dehumidifier

Fig. 1. Schematic of the conventional liquid dehumidifier.

The proposed process is shown in Fig. 2, where the regenerator and dehumidifier are cascaded connected, and the return air is dehumidified by both the surface air cooler and liquid dehumidifier (DEH), named as RCD (Regeneration and Dehumidification Cascaded) process. The return air firstly flows through the regenerator (REG) and is humidified in the regeneration process. Then the air is dehumidified by the surface air cooler and further dehumidified to a certain degree by the $\mathrm{DEH}$ and supplied to the room in the end.

Two kinds of cooling sources are included in this process. $7^{\circ} \mathrm{C}$ chilled water is widely used in buildings, which is directly used as the cooling source in the primary surface cooler. The evaporator of the heat pump provides cooling capacity to the liquid desiccant in the $\mathrm{DEH}$, as the second cooling source. The condenser of the heat pump provides heat to regenerate the liquid desiccant in the REG.

Besides the chilled water, the process is consisted of another three liquid cycles. Firstly, $90 \%$ of the solution flow is self-circulated in the DEH or REG. In order to guarantee enough concentration of the solution to dehumidify the air, the second cycle, interstage flow cycle between these two towers, is involved in the process to ensure the dehumidification ability of the solution, with a flow rate of $10 \%$ of the total solution flow spraying in the REG or DEH. The last cycle is the refrigerant circulating in the heat pump loop.
However, in all of these above previous systems, the regenerator is separated from the dehumidifier, which requires more than one air duct and a complex configuration. Based on the condition where the return air needs to be processed, a novel hybrid deep dehumidification process based on liquid desiccant is proposed to simply the configuration of the system, where the extra air duct for regeneration is discarded. In the process, the humidity ratio of the supplied air can be processed to $2.6 \mathrm{~g} / \mathrm{kg}$. The detailed form of the system and its performance will be revealed in this paper.

\section{General process description}

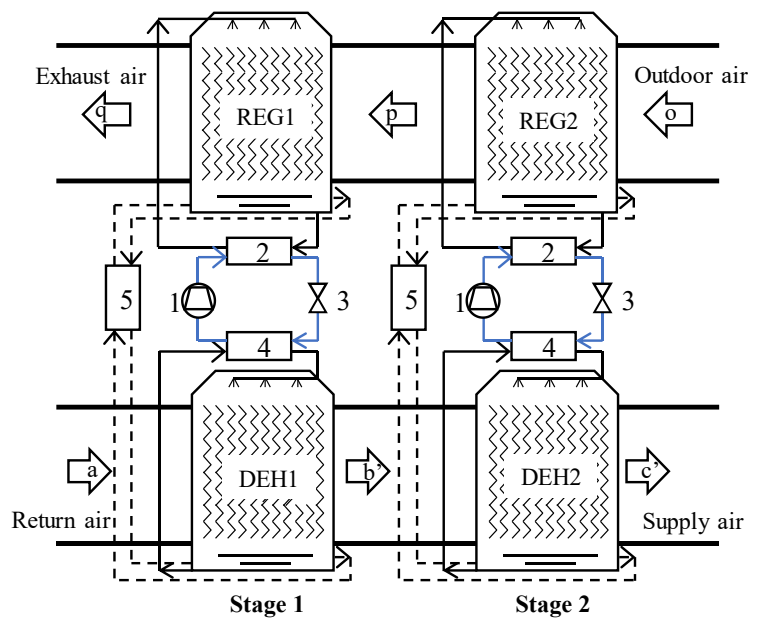

(b) Two-stage liquid dehumidifier

Compared with the conventional process, no extra regeneration air or corresponding air duct are needed in the proposed process, which obviously simplifies the layout of the system.

As for deep dehumidification, solution in the DEH with a high temperature and mass concentration is required to produce supply air with a limited humidity ratio. However, the high concentration of the solution makes it hard to be regenerated in the REG because of the low surface vapour partial pressure, which intends an extreme high condensing temperature of the condenser to heat the solution and provide mass transfer driving force in the REG. The low evaporation temperature below $0^{\circ} \mathrm{C}$ and high $\mathrm{T}_{\mathrm{c}}$ above $50^{\circ} \mathrm{C}$ mean a high compression ratio, which limits the performance of the heat pump. In some conditions, the extreme difference between evaporating temperature and condensing temperature requires a multiple-stage liquid dehumidification system, which greatly complicates the system arrangement and shows restricted energy performance.

The humidification effect of the return air in the REG is important for this RCD process. Obviously, this humidification process increases the dehumidification load of the system, which can be avoided by the conventional system where the solution regenerated by outdoor air. However, the solution is regenerated in a better circumstance in the RCD process because of the 
low humidity ratio of the return air. It intends a lower condensing temperature and a higher $C O P$ of the heat pump, which can be realized by only a single-stage system. The comprehensive effect on the performance of the above disadvantage and advantage will be analysed in Section 4. Under this process, the humidity ratio of the supplied air can be reached as low as $2.6 \mathrm{~g} / \mathrm{kg}$.

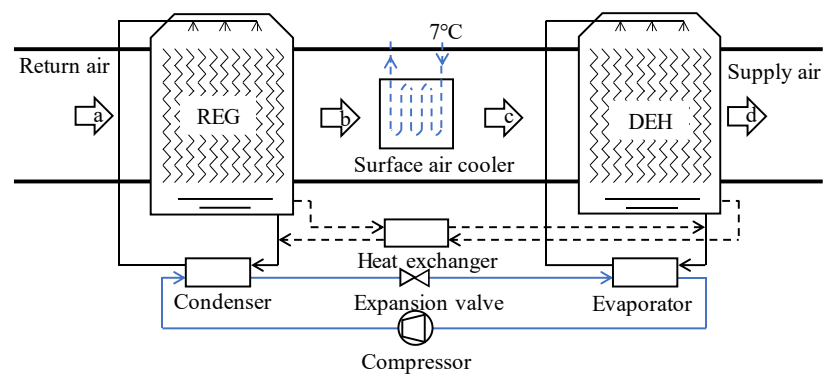

Fig. 2. Schematic of the RCD process.

\section{Model}

A detailed mathematical model is built for the whole process using the Matlab Simulink platform. The models for key components are expressed as following.

\section{(1) Dehumidifier/regenerator}

The dehumidifier and the regenerator are core modules in the whole process. Both of them are cross flow exchangers, where a desiccant solution of lithium bromide $(\mathrm{LiBr})$ is supplied vertically inside the exchangers and the air is supplied perpendicular to it. The validated dehumidifier/regenerator model of Liu et al. [13] is used in this study, its schematic shown as Fig. 3.
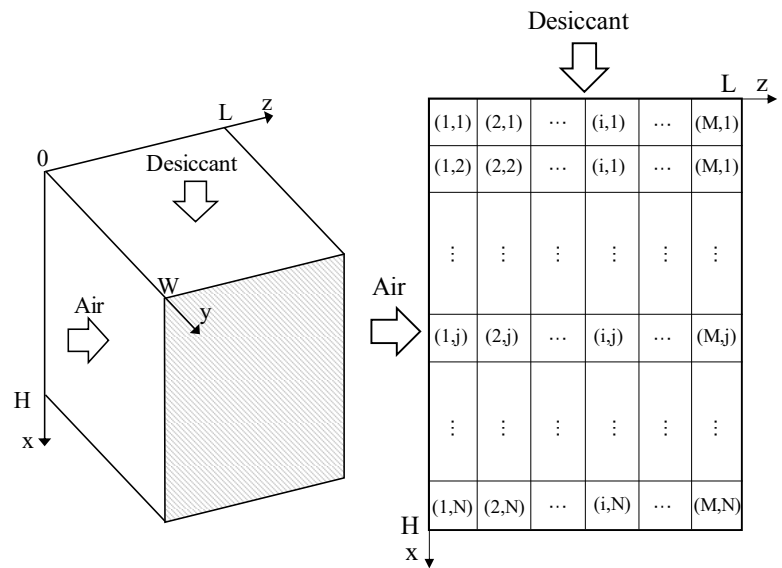

(a) Three dimensional shematic (b) Two dimensional schematic Fig. 3. Schematic of the cross flow dehumidifier/regenerator.

Energy, water content and solute mass balance on a differential element are given as Eqs. (1) (3), respectively.

$$
\begin{gathered}
\dot{m}_{\mathrm{a}}\left(h_{\mathrm{a}, i+1, j}-h_{\mathrm{a}, i, j}\right)=\frac{N}{M}\left(\dot{m}_{\mathrm{s}, i, j} h_{\mathrm{s}, i, j}-\dot{m}_{\mathrm{s}, i, j+l} h_{\mathrm{s}, i, j+1}\right) \\
\dot{m}_{\mathrm{a}}\left(\omega_{\mathrm{a}, i+l, j}-\omega_{\mathrm{a}, i, j}\right)=\frac{N}{M}\left(\dot{m}_{\mathrm{s}, i, j+l}-\dot{m}_{\mathrm{s}, i, j}\right)
\end{gathered}
$$

$$
\dot{m}_{\mathrm{s}, i, j+1} \cdot \xi_{i, j+1}=\dot{m}_{\mathrm{s}, i, j} \cdot \xi_{i, j}
$$

The overall heat and mass transfer between the air and the desiccant is given as Eq. (4):

$$
\frac{\partial h_{\mathrm{a}}}{\partial z}=\frac{N T U \cdot L e}{L} \cdot\left[\left(h_{\mathrm{e}}-h_{\mathrm{a}}\right)+\lambda_{T \mathrm{~s}}\left(\frac{1}{L e}-1\right) \cdot\left(\omega_{\mathrm{e}}-\omega_{\mathrm{a}}\right)\right]
$$

where, Le number is usually assumed to be 1 [14], and $N T U$ is defined as Eq. (5):

$$
N T U=\frac{h_{\mathrm{m}} V}{\dot{m}_{\mathrm{a}}}
$$

The moisture transfer between the air and the desiccant is expressed as:

$$
\frac{\partial \omega_{\mathrm{a}}}{\partial z}=\frac{N T U}{L} \cdot\left(\omega_{\mathrm{e}}-\omega_{\mathrm{a}}\right)
$$

The shadow surface of Fig. 3(a) is divided to meshes equally to numerically solve the above equations as Fig. 3 (b), and the proper mass number depends on the size of dehumidifier/regenerator and required precision. In this study, when the mass number over $50 \times 50$, supply air parameters shows little significant variance with the increase of the mass number. Thereby, a mesh number of $100 \times 100$ is adopted in this study. With known NTU value and air and desiccant inlet parameters, the outlet parameters can be obtained.

\section{(2) Heat pump}

The heat transfer efficiencies of the evaporator and condenser are defined as Eqs. (7) and (8), respectively:

$$
\begin{aligned}
& \eta_{e}=\frac{t_{\mathrm{in}, \mathrm{se}}-t_{\mathrm{out}, \mathrm{se}}}{t_{\mathrm{in}, \mathrm{se}}-t_{\mathrm{e}}} \\
& \eta_{c}=\frac{t_{\mathrm{out}, \mathrm{sc}}-t_{\mathrm{in}, \mathrm{sc}}}{t_{\mathrm{c}}-t_{\mathrm{in}, \mathrm{sc}}}
\end{aligned}
$$

Cooling and heating capacities provided by the evaporator and condenser are given as Eqs. (9) and (10), respectively:

$$
\begin{aligned}
& Q_{e}=\left(t_{\text {in,se }}-t_{\text {out }, \mathrm{se}}\right) \cdot \dot{m}_{\mathrm{DEH}, \mathrm{s}} \\
& Q_{c}=\left(t_{\mathrm{out}, \mathrm{sc}}-t_{\mathrm{in}, \mathrm{sc}}\right) \cdot \dot{m}_{\mathrm{REG}, \mathrm{s}}
\end{aligned}
$$

$C O P$ equation of the heat pump is given as Eq. (11):

$$
\frac{Q_{\mathrm{e}}}{Q_{\mathrm{c}}-Q_{\mathrm{e}}}=\frac{T_{\mathrm{e}}}{T_{\mathrm{c}}-T_{\mathrm{e}}} \cdot D
$$

where $D$ is thermodynamic perfection degree, and it is conservatively assumed to be 0.6 when the humidity ratio of the supply air processed to around $3 \mathrm{~g} / \mathrm{kg}$. Then, $t_{\text {out }, \text { se }}, t_{\text {out }, s c}, Q_{\mathrm{e}}, Q_{\mathrm{c}}$ and $T_{\mathrm{c}}$ can be figured out according to Eqs. (7) (11), when inlet parameters, $t_{\mathrm{e}}$, and $D$ given.

\section{Process performance and discussion}

\subsection{Process characteristics}

In the proposed RCD process, air parameters at different positions in Fig. 2 are shown in Fig. 4. The REG humidifies the return air from state $a$ to state $b$, and the air is firstly handled to state $c$ by the surface cooler and 
then further dehumidified to state $d$ by the liquid dehumidifier. In the conventional two-stage process, air parameters at different positions in supply air duct and exhaust air duct in Fig. 1(b) are also shown in Fig. 4 [7]. The return air is dehumidified to $b^{\prime}$ by the DEH1 and then to $c$ ' by the DEH2, while the outdoor air at state $o$ is humidified to state $p$ by the REG2, and then to state $q$ by the REG1.

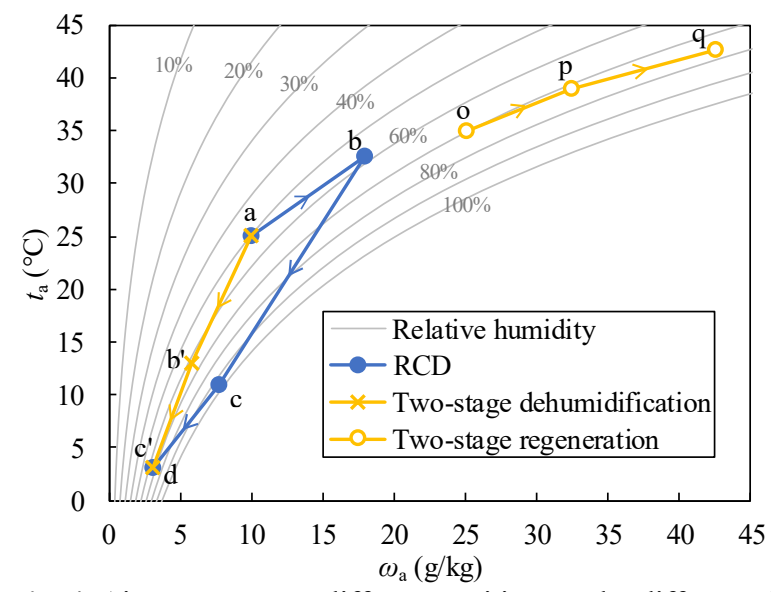

Fig. 4. Air parameters at different positions under different air handling processes.

The air state of humidity ratio in the supply air duct is depicted in Fig. 5. In Fig. 5, the abscissa refers to the absolute value of the change of air humidity ratio during the step. The dehumidification in the upper area is easy to realize by the condensing dehumidifier surface air cooler. And the position of $c$ indicates the limited depth of the condensing dehumidifier with $7^{\circ} \mathrm{C}$ chilled water. Dehumidification in the lower area is hard to reach, which needs much more cost. The lower, the harder. Therefore, the basic idea of the RCD process is to make full use of the condensing dehumidifier in the upper area, even at the expense of increasing cooling load, to reduce the use of liquid dehumidifier, and to provide good regeneration conditions to realize energy conservation in the liquid dehumidifier.

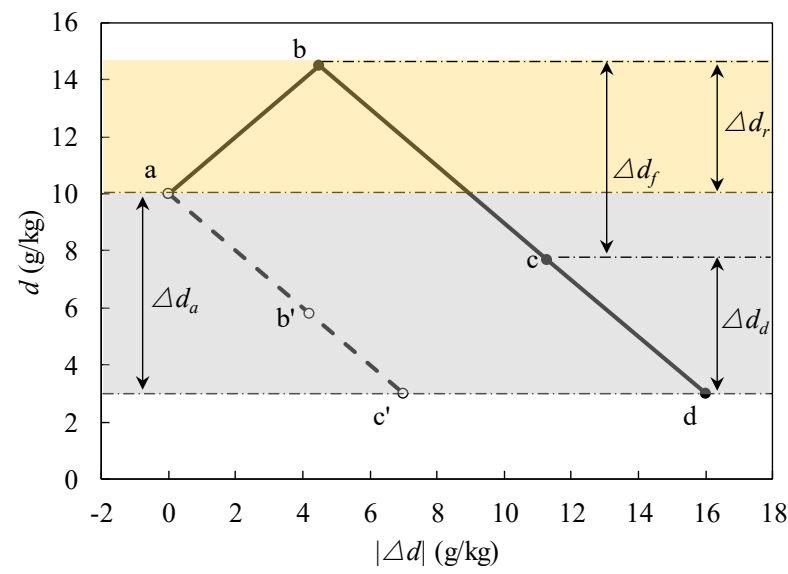

Fig. 5. Variation of air humidity ratio during the RCD process and conventional two-stage process.
In Fig. 5, the conventional process handles the air just within $\Delta d_{\mathrm{a}}$ between the humidity ratio of the return air (state $a$ ) and that of the supply air (state $c^{\prime}$ ). However, the RCD process expands the range of the humidity of the handled air. In the RCD process, the total load is undertaken by the surface cooler $\left(\Delta d_{\mathrm{f}}\right)$ and the DEH $\left(\Delta d_{\mathrm{d}}\right)$. Although the dehumidification load is increased by $\Delta d_{\mathrm{r}}$, a better regeneration circumstance ensures a better performance of the heat pump and avoids the use of a multiple-stage system. In addition, the additional $\Delta d_{\mathrm{r}}$ is covered by $\Delta d_{\mathrm{f}}$, which means the the increasing load is removed by the condensing dehumidifier, which consumes less power than liquid dehumidifier when handing the same load in this humidity level. In the meanwhile, condensing dehumidifier surface cooler helps reduce the load of the liquid dehumidifier from $\Delta d_{\mathrm{a}}$ to $\Delta d_{\mathrm{d}}$ because of $\Delta d_{\mathrm{f}}$ larger than $\Delta d_{\mathrm{r}}$. And the integrated energy performance will be revealed in Section 4.3 .

\subsection{Influencing factors}

\subsubsection{Desiccant flow rate}

The volume flow rate of the return air is assumed to be $3000 \mathrm{~m}^{3} / \mathrm{h}$, its temperature to be $25^{\circ} \mathrm{C}$ and its humidity ratio to be $10.0 \mathrm{~g} / \mathrm{kg}$. Chilled water is set at $7^{\circ} \mathrm{C}$ and condensing temperature of the heat pump is set as $3^{\circ} \mathrm{C}$. The solution rate in the DEH is the same as that in the REG. Given different solution flow rates in the DEH, the humidity ratio of the outlet supply air varies as Fig. 6, along with the enthalpy difference between air inlet and outlet.

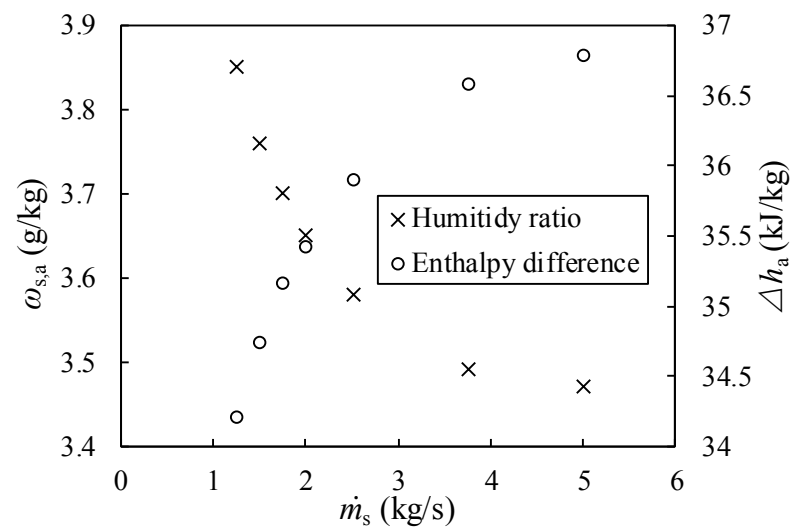

Fig. 6. Humidity ratio of the supply air and enthalpy difference between air inlet and outlet varying with solution flow rate.

The supply air is handled to a lower humidity ratio with a larger solution flow rate. When the solution flow rate increases from $1.3 \mathrm{~kg} / \mathrm{s}$ to $5.0 \mathrm{~kg} / \mathrm{s}$, the humidity ratio of the supply air decreases from $3.9 \mathrm{~g} / \mathrm{kg}$ to 3.5 $\mathrm{g} / \mathrm{kg}$. The decreasing rate of the humidity ratio is slowed down with the solution flow rate increasing. When the solution flow rate above $3 \mathrm{~kg} / \mathrm{s}$, the current solution flow rate is enough to process the return air, and the extra flow rate shows limited effect on the improvement of the processing depth in humidity ratio. In this study, the 
processing depth is prior to the energy consumption of the solution pump, therefore, a solution flow rate of 3.8 $\mathrm{kg} / \mathrm{s}$ is selected in the flowing sections.

\subsubsection{Evaporation temperature of the heat pump}

Evaporation temperature of the heat pump directly influences the temperature of liquid desiccant in the DEH, which determines the processing depth of the supply air. The volume flow rate of the return air is assumed to be $3000 \mathrm{~m}^{3} / \mathrm{h}$, its temperature to be $25^{\circ} \mathrm{C}$ and its humidity ratio to be $10.0 \mathrm{~g} / \mathrm{kg}$. Chilled water is set at $7^{\circ} \mathrm{C}$ and the solution flow rate is set as $3.8 \mathrm{~kg} / \mathrm{s}$. Given different values of evaporation temperature, the humidity ratio of the outlet supply air varies as Fig. 7, along with the enthalpy difference between air inlet and outlet.

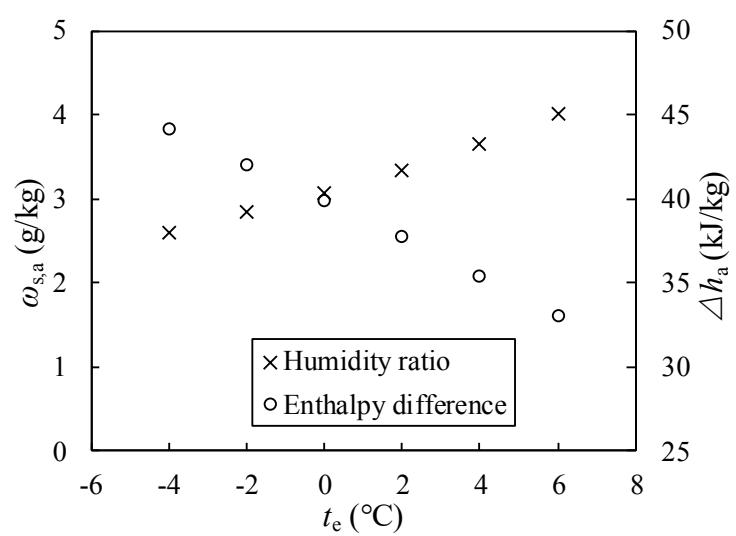

Fig. 7. Humidity ratio of the supply air and enthalpy difference between air inlet and outlet varying with evaporation temperature.

The supply air is handled to a lower humidity ratio with a lower value of $t_{e}$. When the value of $t_{e}$ descends from $6^{\circ} \mathrm{C}$ to $-4^{\circ} \mathrm{C}$, the humidity ratio of the supply air decreases from $4.0 \mathrm{~g} / \mathrm{kg}$ to $2.6 \mathrm{~g} / \mathrm{kg}$.

Under this process, the limitation of processing depth can be concluded to two aspects: (1) Crystallization curve of the LiBr solution; (2) The local air temperature above $0^{\circ} \mathrm{C}$ to avoid freezing. As for the first aspect, when the ambient temperature is $-30^{\circ} \mathrm{C}, \mathrm{LiBr}$ solution will not crystallize with a mass concentration range of $28.6 \% \sim 51.2 \%$ [15]. Secondly, the lowest temperature appears at the outlet supply air in the whole process. In order to ensure its temperature above $0^{\circ} \mathrm{C}$, the $t_{e}$ of the heat pump should be above $-4^{\circ} \mathrm{C}$. Under the above two considerations, the supply air can be handled to as low as $2.6 \mathrm{~g} / \mathrm{kg}$ with $t_{e}$ of $-4^{\circ} \mathrm{C}$.

\subsection{Energy performance}

Assuming the humidity ratio of the supply air needs to be processed to $3 \mathrm{~g} / \mathrm{kg}$. Energy performance of the proposed RCD process and the conventional two-stage liquid dehumidifier process is compared in Table 1. Ignoring energy consumption of transmission and distribution, the $C O P$ is only calculated by Eqs. (12) and (13):

$$
\begin{gathered}
C O P_{\text {two-stage }}=\frac{\left(h_{\mathrm{r}, \mathrm{a}}-h_{\mathrm{s}, \mathrm{a}}\right) \cdot \dot{m}_{\mathrm{a}}}{P} \\
C O P_{\mathrm{RDC}}=\frac{\left(h_{\mathrm{r}, \mathrm{a}}-h_{\mathrm{s}, \mathrm{a}}\right) \cdot \dot{m}_{\mathrm{a}}}{P+\frac{\left(h_{\mathrm{sur}, \mathrm{in}}-h_{\text {sur }, \text { out }}\right) \cdot \dot{m}_{\mathrm{a}}}{C O P_{\text {chiller }}}}
\end{gathered}
$$

where $h_{\mathrm{s}, \mathrm{a}}$ is the enthalpy of the supply air; $h_{\mathrm{r}, \mathrm{a}}$ is the enthalpy of the return air; $P$ is the energy consumption of the heat pump; $h_{\text {sur,in }}$ is the enthalpy of the air at the inlet of the surface air cooler; $h_{\text {sur,out }}$ is the enthalpy of the air at the outlet of the surface air cooler; $C O P_{\text {chiller }}$ is the $C O P$ of the chiller providing $7^{\circ} \mathrm{C}$ chilled water, which is taken as of 6.1 when assuming $t_{\mathrm{e}}$ of $5^{\circ} \mathrm{C}, t_{\mathrm{c}}$ of $37^{\circ} \mathrm{C}$ and thermodynamic perfection of 0.6 .

The heat pump is the main energy-consuming component in the conventional process, while the chiller providing $7^{\circ} \mathrm{C}$ chilled water is the other energyconsuming component in the RCD process. The volume flow rate of the return air is assumed to be $3000 \mathrm{~m}^{3} / \mathrm{h}$, its temperature to be $25^{\circ} \mathrm{C}$ and its humidity ratio to be 10.0 $\mathrm{g} / \mathrm{kg}$. Based on Eqs. (12) and (13), COP of the conventional process is between 2.2 2.5 with different outdoor parameters, while $C O P$ of the proposed process is 2.9. As for the conventional process, the performance deteriorates with the increase of both outdoor air temperature and humidity. Because of no extra regeneration air or corresponding air duct in the RCD process, the $C O P$ of the proposed process is a constant under different outdoor air conditions. Therefore, the energy consumption of the RCD process is lower than the traditional two-stage process by $13.8 \% \sim 24.1 \%$ under different outdoor conditions, with a processing depth of $3.0 \mathrm{~g} / \mathrm{kg}$. With the increase of the processing depth, its effect on energy conservation will be more obvious. When the humidity ratio of the supply required to be 2.6 $\mathrm{g} / \mathrm{kg}$, energy consumption will be saved by $17.5 \sim 29.2 \%$ in the RCD process, compared with that in the conventional two-stage process.

\section{Conclusion}

A novel deep dehumidification process (RCD) using liquid desiccant has been proposed in this study, where the REG and DEH are cascaded and surface air cooler is used between these two modules. Energy and mass equations are used to do the modelling, and the performance of the proposed RCD process is then investigated. Main conclusions are listed as following:

(1) No extra regeneration air or corresponding air duct are needed in the proposed process, which obviously simplifies the layout of the system. Although the REG increasing the dehumidification load, the surface cooler undertakes all the additional load and reduces the load of the liquid dehumidier. In addition, return air regenerating the desiccant guarantees a good performance of the heat pump.

(2) The desiccant flow rate shows positive effect on the processing depth of the supply air. The decreasing rate of the humidity ratio is slowed down with the solution flow rate increasing. The evaporation temperature shows negative effect on the processing depth of the supply air. 
(3) In consideration of the crystallization of the $\mathrm{LiBr}$ solution and the risk of freezing, the lowest humidity ratio can be reached to $2.6 \mathrm{~g} / \mathrm{kg}$, with an evaporation

Table 1. Simulation results of the conventional two-stage process and proposed RCD process.

\begin{tabular}{|c|c|c|c|c|c|c|c|c|c|c|c|c|}
\hline & \multicolumn{6}{|c|}{ Air } & \multicolumn{5}{|c|}{ Heat pump } & \multirow{4}{*}{$\mathrm{COP}$} \\
\hline & \multirow{2}{*}{\multicolumn{2}{|c|}{ Outdoor }} & \multirow{2}{*}{\multicolumn{2}{|c|}{$\begin{array}{c}\text { After DEH1 } \\
\text { After surface cooler }\end{array}$}} & \multirow{2}{*}{\multicolumn{2}{|c|}{ Supply }} & \multicolumn{2}{|c|}{ Evaporator } & \multicolumn{2}{|c|}{ Condenser } & \multirow[t]{2}{*}{ Power } & \\
\hline & & & & & & & Stage 1 & Stage 2 & Stage 1 & Stage 2 & & \\
\hline & $\mathrm{T}$ & $\mathrm{d}$ & $\mathrm{T}$ & $\mathrm{d}$ & $\mathrm{T}$ & $\mathrm{d}$ & \multicolumn{2}{|c|}{$\mathrm{T}_{\mathrm{e}}$} & \multicolumn{2}{|c|}{$\mathrm{T}_{\mathrm{c}}$} & $P$ & \\
\hline & ${ }^{\circ} \mathrm{C}$ & $\mathrm{g} / \mathrm{kg}$ & ${ }^{\circ} \mathrm{C}$ & $\mathrm{g} / \mathrm{kg}$ & ${ }^{\circ} \mathrm{C}$ & $\mathrm{g} / \mathrm{kg}$ & \multicolumn{2}{|c|}{${ }^{\circ} \mathrm{C}$} & \multicolumn{2}{|c|}{${ }^{\circ} \mathrm{C}$} & $\mathrm{W}$ & \\
\hline \multirow{4}{*}{$\begin{array}{l}\text { Two- } \\
\text { stage }\end{array}$} & 35 & 30 & 13.1 & 5.9 & 3.5 & 3.2 & 5.4 & -3.1 & 53.3 & 48.9 & 17.4 & 2.2 \\
\hline & 35 & 25 & 12.9 & 5.9 & 3.1 & 3.1 & 5.2 & -3.5 & 52.0 & 47.1 & 16.8 & 2.4 \\
\hline & 35 & 20 & 12.8 & 5.8 & 2.7 & 3.0 & 4.9 & -4.0 & 50.5 & 45.2 & 16.3 & 2.5 \\
\hline & 30 & 20 & 12.7 & 5.8 & 2.5 & 3.0 & 4.8 & -4.2 & 49.9 & 44.3 & 16.0 & 2.5 \\
\hline $\mathrm{RCD}$ & - & - & 10.8 & 7.7 & 3.0 & 3.0 & \multicolumn{2}{|c|}{0.0} & \multicolumn{2}{|c|}{36.0} & 5.9 & 2.9 \\
\hline
\end{tabular}

temperature of $-4^{\circ} \mathrm{C}$.

(4) The proposed RCD process shows competitive energy performance. Compared with the traditional twostage liquid desiccant process, energy consumption can be saved by $17.5 \sim 29.2 \%$ under the RCD process with the supplied humidity ratio of $2.6 \mathrm{~g} / \mathrm{kg}$.

The experimental apparatus is under construction, and the experimental result will be investigated and compared with the present simulated results in the further study. Moreover, because of the low temperature of the outdoor supply air, the sensible heat recovery device will be installed between the outlet of the REG and the outlet of the $\mathrm{DEH}$, and the experimental performance of the proposed process with heat recovery device will be also revealed in the further study.

The research described in this paper is supported by the National Key Research Program of China (No. 2018YFC0705202 and No. 2018YFC0705203) and National Natural Science Foundation of China (No.51608296 and No. 51521005).

\section{References}

1. M.M. Rafique, P. Gandhidasan, H.M.S. Bahaidarah, Renew. Sustain. Energy Rev. 56, 17 (2016).

2. D.G. Waugaman, A. Kini, C.F. Kettleborough, J. Energy Resour. Technol. 115, 1 (1993).

3. W.Kessling, E. Laevemann, C. Kapfhammer, Sol. Energy 64, 4-6, (1998).

4. C. Martin, D.Y. Goswami, J. Sol. Energy Eng. 121,3 (1999).

5. R.M. Lazzarin, F. Castellotti. Energy \& Buildings 39, 1 (2007).

6. X.H. Liu, Z. Li, Y. Jiang, HVAC 34, 11 (2004).

7. H.Q. Zhang, X.H. Liu, Y. Jiang, JSEU_EE 26, 2 (2010).

8. Y. Chen, Y. Luo, H. Yang, Energy Procedia 105, 6 (2017).

9. W. Su, X. Zhang, Appl. Therm. Eng. 115, 11 (2017).

10. B. Su, W. Qu, W. Han, Energ. Convers. Manage. 163, 11 (2018).
11. N. Shan, Y. Yin, X. Zhang, Appl. Energ. 219, 13 (2018).

12. K. Thu, S. Mitra, B.B. Saha, Appl. Energ. 213, 14 (2018)

13. X.H. Liu, Y. Jiang, K.Y. Qu, Energ. Convers. Manage. 48, 2 (2007).

14. S. Jain, P.L. Dhar, S.C. Kaushik, Appl. Therm. Eng. 20, 3 (2000).

15. K.R. Patil, A.D. Tripathi, G. Pathak, S.S. Katti, J. Chem. Eng. Data 85 (1979). 


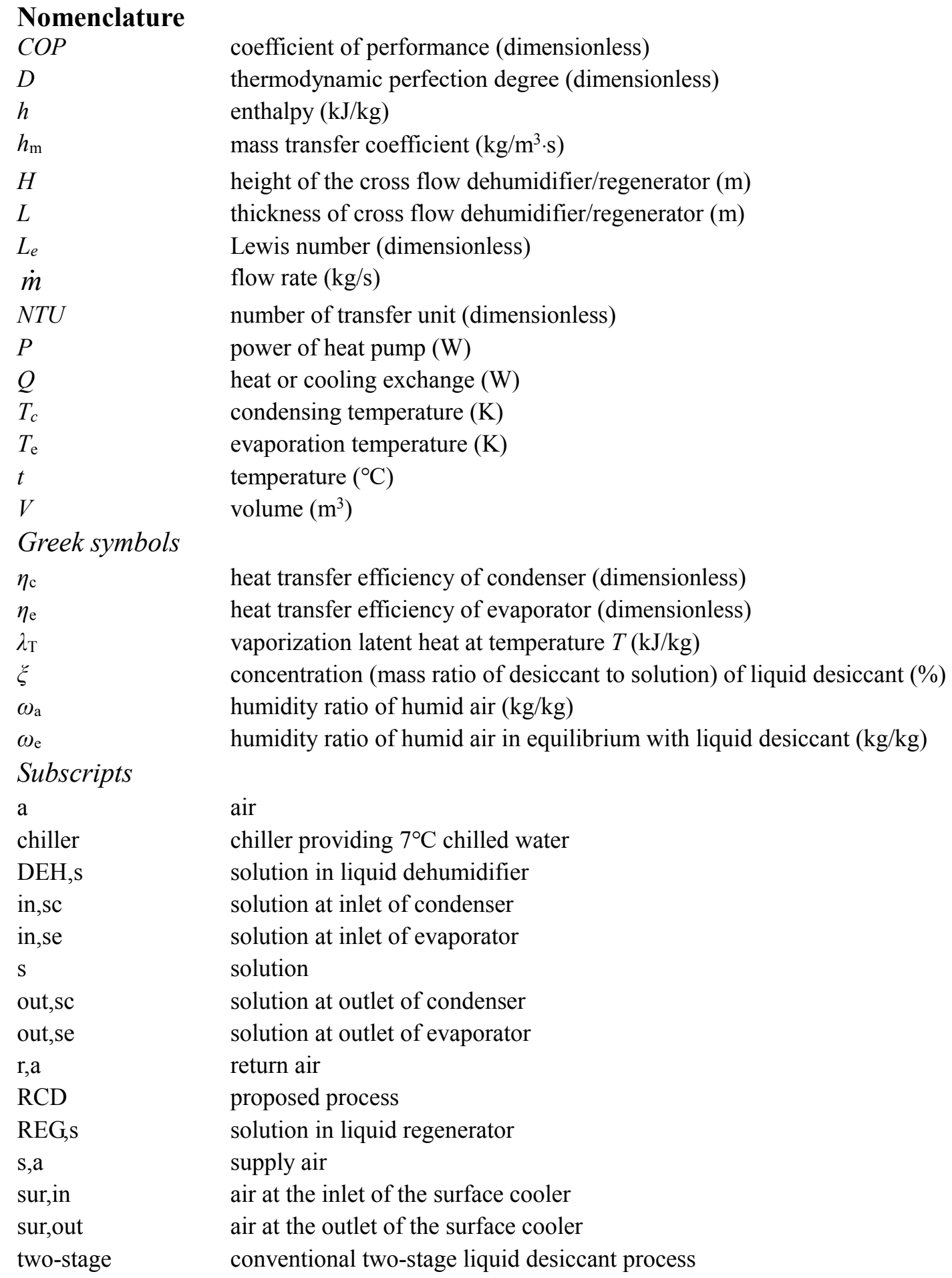




\section{Reviewer \#1:}

The paper presents numerical results concerning the performance of a dehumidification process using liquid desiccant inside a heat pump in order to simplify the arrangement of air ducts and obtain energy efficiency.

The paper is very interesting and well written.

However, please find here below minor suggestions:

(1) Specify the numerical software for the simulations

Reply: Thank you for your comment. Matlab Simulink platform is used for the simulation, and this information has been updated in the revised manuscript.

(2) There are some mesh analysis in order to choose the final one of 100x100 cells?

Reply: Thank you for your comment. According to your advice, the corresponding illustration has been updated: "The shadow surface of Fig. 3(a) is divided to meshes equally to numerically solve the above equations as Fig. 3(b), and the proper mass number depends on the size of dehumidifier/regenerator and required precision. In this study, when the mass number over $50 \times 50$, supply air parameters shows little significant variance with the increase of the mass number. Thereby, a mesh number of $100 \times 100$ is adopted in this study."

(3) The literature analysis can be more comprehensive

Reply: Thank you for your comment. Studies of liquid desiccant-based hybrid air-conditioning systems in last two years have been updated in the third paragraph in the revised manuscript.

"In recent years, hybrid dehumidification systems using liquid desiccant have become popular owing to a reduction in their energy consumption. Chen et al. [8] investigated on a hybrid desiccant dehumidification and evaporative cooling system with partial circulation air was explored by fully making use of dry return air from air-conditioned space, and an attractive energy saving ratio of $23.5 \%$ could be achieved under Hong Kong weather condition, compared with the conventional vapour compression air-conditioning system. Su and Zhang [9] proposed a hybrid compressionabsorption refrigeration air-conditioning system combined with liquid desiccant dehumidification, the primarily energy efficiency of the system was $34.97 \%$ higher than that of traditional absorption refrigeration air-conditioning system at the same operation condition. Su et al. [10] developed a novel liquid desiccant system integrated with a concentrated photovoltaic/thermal collector for deep dehumidification. Simulation studies indicated the proposed system has a superior power saving ability of 55.65\% comparing with the conventional one. Shan et al. [11] proposed a hybrid refrigerant system consisting of a conventional chiller combined with a liquid desiccant dehumidification and evaporative cooling subsystem in summer, and the electric coefficient of performance of the system was revealed 10.3\% higher than the conventional vapour compression system. Thu et al. [12] evaluated the feasibility of hybrid dehumidification + mechanical vapour compression systems. It was demonstrated that the break-even COP for the dehumidifier ranges from 9 to 17 (Carnot approach) and 4.3 to 6.8 (ideal cycle), depending on the requirement of the outdoor air ratio and the temperature of the supply air."

\section{Reviewer \#2:}

The paper deals with a novel dehumidification system using liquid desiccant. It is well written. Literature is poor. equations 1,2 3 and 5 have bad symbols!!!

The study is mainly based on numerical results;

\section{(1) Literature is poor.}

Reply: Thank you for your comment. Studies of liquid desiccant-based hybrid air-conditioning systems in last two years have been updated in the third paragraph in the revised manuscript:

"In recent years, hybrid dehumidification systems using liquid desiccant have become popular owing to a reduction in their energy consumption. Chen et al. [8] investigated on a hybrid desiccant dehumidification and evaporative cooling system with partial circulation air was explored by fully making use of dry return air from air-conditioned space, and an attractive energy saving ratio of $23.5 \%$ could be achieved under Hong Kong weather condition, compared with the conventional vapour compression air-conditioning system. Su and Zhang [9] proposed a hybrid compression- 
absorption refrigeration air-conditioning system combined with liquid desiccant dehumidification, the primarily energy efficiency of the system was 34.97\% higher than that of traditional absorption refrigeration air-conditioning system at the same operation condition. Su et al. [10] developed a novel liquid desiccant system integrated with a concentrated photovoltaic/thermal collector for deep dehumidification. Simulation studies indicated the proposed system has a superior power saving ability of 55.65\% comparing with the conventional one. Shan et al. [11] proposed a hybrid refrigerant system consisting of a conventional chiller combined with a liquid desiccant dehumidification and evaporative cooling subsystem in summer, and the electric coefficient of performance of the system was revealed $10.3 \%$ higher than the conventional vapour compression system. Thu et al. [12] evaluated the feasibility of hybrid dehumidification + mechanical vapour compression systems. It was demonstrated that the break-even COP for the dehumidifier ranges from 9 to 17 (Carnot approach) and 4.3 to 6.8 (ideal cycle), depending on the requirement of the outdoor air ratio and the temperature of the supply air."

(2) Equations 1,2 3 and 5 have bad symbols!

Reply: Thank you for your comment. For better understanding these four equations, corresponding expressions have been revised, in addition to Fig. 3:

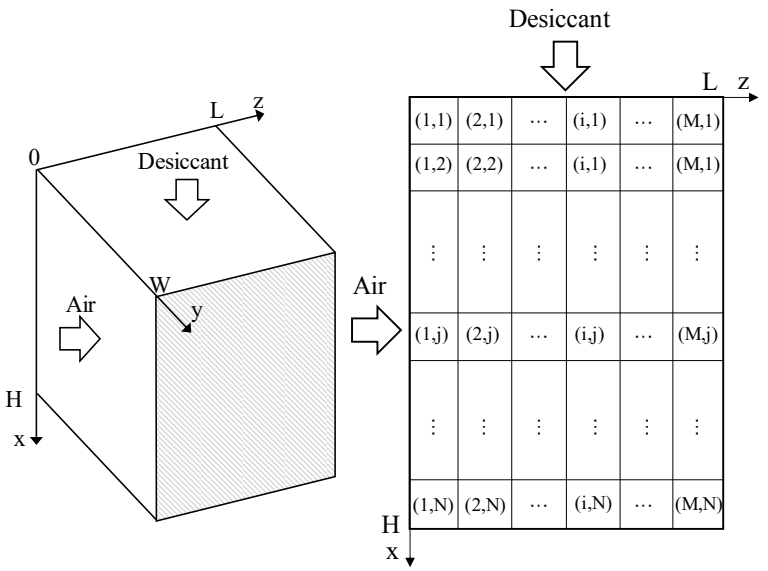

(a) Three dimensional shematic (b) Two dimensional schematic

Fig. 3. Schematic of the cross flow dehumidifier/regenerator.

$$
\begin{gathered}
\dot{m}_{\mathrm{a}}\left(h_{\mathrm{a}, i+1, j}-h_{\mathrm{a}, i, j}\right)=\frac{N}{M}\left(\dot{m}_{\mathrm{s}, i, j} h_{\mathrm{s}, i, j}-\dot{m}_{\mathrm{s}, i, j+1} h_{\mathrm{s}, i, j+1}\right) \\
\dot{m}_{\mathrm{a}}\left(\omega_{\mathrm{a}, i+1, j}-\omega_{\mathrm{a}, i, j}\right)=\frac{N}{M}\left(\dot{m}_{\mathrm{s}, i, j+1}-\dot{m}_{\mathrm{s}, i, j}\right) \\
\dot{m}_{\mathrm{s}, i, j+1} \cdot \xi_{i, j+1}=\dot{m}_{\mathrm{s}, i, j} \cdot \xi_{i, j} \\
N T U=\frac{h_{\mathrm{m}} V}{\dot{m}_{\mathrm{a}}}
\end{gathered}
$$

